Proc. Indian Acad. Sci. (Earth Planet. Sci.), Vol. 93, No. 2, July 1984, pp. 129-133.

(C) Printed in India.

\title{
Migration of the dip equator in the Indian region
}

\author{
A V S MURTY*, K AHMED and D R K RAO \\ Indian Institute of Geomagnetism, Colaba, Bombay 400005, India \\ *Present address: Oil and Natural Gas Commission, Nazira, Assam, India
}

MS received 21 June 1983; revised 29 May 1984

\begin{abstract}
The position of the dip equator (DE) is worked out in the Indian region based on fairly close geomagnetic measurements made during a survey in the year 1981 . The DE is located about $24 \mathrm{~km}$ south of its 1971 position along the $77.5^{\circ} \mathrm{E}$ meridian. Also, the DE positions for the epochs 1971 and 1981 show closeness on the east coast of India when compared to its west coast positions. The DE positions inferred from the repeat observations since 1909 are used for estimating the pattern of migration and the results are discussed.
\end{abstract}

Keywords. Dip-equator; migration; geomagnetic measurements.

\section{Introduction}

The geographic setting of India is unique in that the northern focus of the $\mathrm{Sq}$ current system and the magnetic dip equator, which are manifestations of the geomagnetic field of external and internal origins respectively, are located in the sub-continent. Seasonal movement of the Sq-focus is known to affect the geomagnetic field variations at low latitudes (Tarpley 1973).

The equatorial ionospheric currents during daytime are concentrated over the magnetic dip equator and the associated geomagnetic phenomena are enhanced near the dip equator (Sugiura 1953; Yacob 1966; Sastri and Jayakar 1970 etc.). Also, the causes for other related phenomena like counter electrojet (Rastogi 1974), generation and enhancement of the negative impulse before a positive sudden commencement SSC $(-+)$ at stations near the magnetic equator (Rastogi and Sastri 1974), etc., are sought for in the equatorial ionospheric region. Thus it becomes essential that the position of the dip equator be determined precisely from time to time.

The long-term shifts of the dip equator in the Indian region have been studied earlier, among others, by Chatterjee (1970), Sanker Narayan and Ramanujachary (1971), IIG, NGRI and SOI (1972) and Srivastava and Habiba Abbas (1977). These studies were based on either magnetic charts, data from a few repeat stations, or on magnetic recordings at a few equatorial stations in selected longitudinal zones. For the first time magnetic field measurements at about 30 stations with near-zero dip values over different longitudinal zones have been used by us in determining the latest position of the dip equator, the details of which are presented here.

\section{Data and analysis}

A magnetic survey was conducted in south India during early 1981 for delineation of subsurface geological structures and for accurate determination of the position of the 
dip equator. Absolute values of the total field $(F)$ and its vertical component $(Z)$ were measured, using a proton precession magnetometer (PPM) and a digital fluxgate magnetometer respectively at 520 stations with a spacing of 8 to $10 \mathrm{~km}$. The stations were so chosen as to attain even distribution over different longitudinal zones, as far as possible, over an area of about $42000 \mathrm{~km}^{2}$ lying to the south of $10^{\circ} \mathrm{N}$ geographical latitude. Care was taken to avoid observations on disturbed days.

From the $F$ and $Z$ observations at each station the horizontal component $(H)$ values were computed. The $H$ and $Z$ data were then corrected for the diurnal magnetic variation, using the hourly values at the magnetic observatories at Trivandrum, Etaiyapuram and Annamalainagar. The abbreviations and geographic coordinates of the observatories and other places mentioned in this note are given in table 1 . The hourly values on each day of the field work were harmonically analysed and values for each minute of the day were computed. While correcting the $H$-data, the $H$-ranges at the time of observation at each of the field stations were computed at ANR and TRD, with respect to the pre-dawn field level. The diurnal ranges at the latitudes of each station were obtained by interpolating between the corresponding $H$-ranges at ANR and TRD, for stations in between the two observatory latitudes. With the availability of $Z$-data from ETP, the $Z$-ranges at each of the station latitudes were obtained by interpolating between the $Z$-ranges at the respective observation times at TRV and ETP for the stations located between the two; and between the corresponding $Z$-ranges at ETP and ANR for the stations north of ETP. For stations lying to the south of TRD, the diurnal $H$ and $Z$ ranges at the respective observation times at TRV were assumed to be valid in view of the earlier comparative studies of the diurnal characteristics at TRD and Kanyakumari by Murty et al (1975). The station values thus corrected for diurnal variations, now represent the main magnetic field, essentially of internal origin, at the station locations.

From these corrected $H$ and $Z$ values the magnetic inclination (dip) at each station was computed. The field stations with dip angles between $-0 \cdot 1^{\circ}$ and $+0.1^{\circ}$ are marked on the map and a line drawn joining the stations with near-zero dip values (figure 1).

\section{Results and discussion}

Based on isomagnetic charts and repeat magnetic observations at field stations Chatterjee (1970) pointed out that the magnetic equator in the Indian region had shifted towards south from the year 1909 to 1920 and from then on it steadily shifted

Table 1. Coordinates of the observatories and other places mentioned in the text.

\begin{tabular}{llcccc}
\hline Observatory & Abbreviation & $\begin{array}{c}\text { Geog. latitude } \\
(\mathrm{N})\end{array}$ & $\begin{array}{c}\text { Geog. longitude } \\
(\mathrm{E})\end{array}$ \\
\hline Trivandrum & TRD & $8^{\circ}$ & $29^{\prime}$ & $76^{\circ}$ & $57^{\prime}$ \\
Etaiyapuram & ETP & $9^{\circ}$ & $09^{\prime}$ & $78^{\circ}$ & $00^{\prime}$ \\
Kodaikanal & KOD & $10^{\circ}$ & $14^{\prime}$ & $77^{\circ}$ & $28^{\prime}$ \\
Annamalainagar & ANR & $11^{\circ}$ & $22^{\prime}$ & $79^{\circ}$ & $41^{\prime}$ \\
Alibag & ABG & $18^{\circ}$ & $38^{\prime}$ & $72^{\circ}$ & $52^{\prime}$ \\
Tirunelveli & & $8^{\circ}$ & $44^{\prime}$ & $77^{\circ}$ & $43^{\prime}$ \\
Sankerankovil & & $9^{\circ}$ & $10^{\prime}$ & $77^{\circ}$ & $31^{\prime}$ \\
Mandapam & & $9^{\circ}$ & $17^{\prime}$ & $79^{\circ}$ & $08^{\prime}$ \\
\hline
\end{tabular}




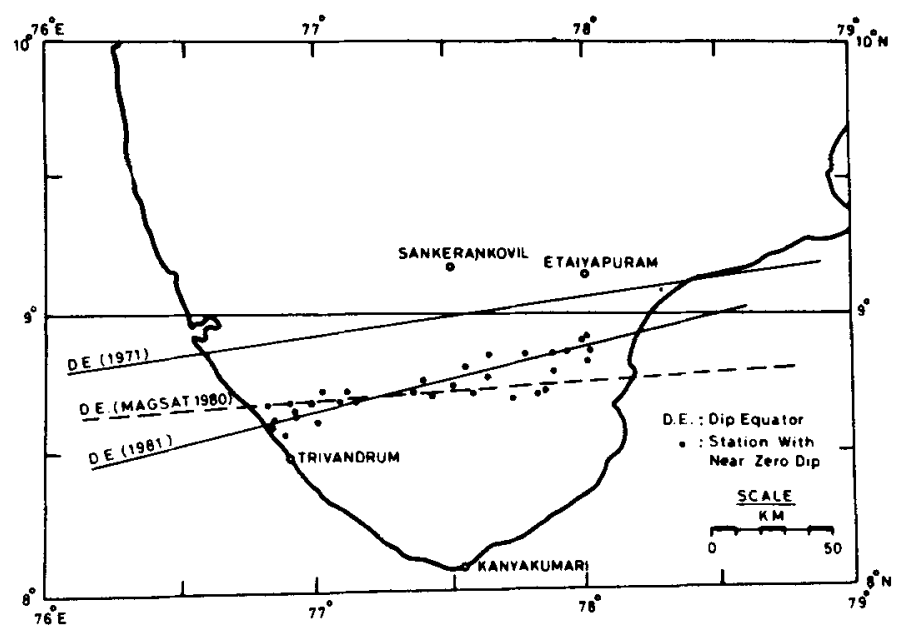

Figure 1. Positions of DE for the epochs, 1971 by IIG, NGRI and sOI, 1980 as computed from MAGSAT spherical harmonic coefficients, and 1981 survey results reported in this communication.

northward and in 1965 the dip equator passed very near Tirunelveli. Sanker Narayan and Ramanujachary (1971) showed that the dip equator was located to the north of Tirunelveli during 1970, based on a vertical magnetic survey, along $4 \mathrm{~N}-\mathrm{S}$ profiles. Based on IGRF model, Cain (1969) showed that for the epoch 1970, the dip equator in India passed further north, viz. north of Sankerankovil. Later, the results of a joint geomagnetic survey during 1971, by IIG, Bombay, NGRI, Hyderabad and soI, Dehradun (1972) showed that the dip equator passed very close to $9^{\circ} \mathrm{N}$ (geog. lat.) on the longitude $77.5^{\circ} \mathrm{E}$ for the epoch 1971 . The recent study, by Srivastava and Habiba Abbas (1977), of the secular variation of $Z$ at the Indian equatorial stations viz., ANR, TRD and KOD suggests that the dip equator migrated to the south from 1968 onwards, though the actual estimates for 1970 and 1971 mentioned earlier, indicate a northward movement up to 1971. The latest position determined for the epoch 1981 based on atleast 30 equatorial stations with near-zero dip values, distributed over different longitudinal zones, is about $24 \mathrm{~km}$ to the south of the 1971 position along the $77.5^{\circ} \mathrm{E}$ longitude. Also, the inclination of the present dip equator to the $9^{\circ}$ parallel is at variance with that of the 1971 dip equator, the values being $13^{\circ}$ and $7^{\circ}$ respectively. Thus, the two dip equators are closer on the east coast as compared to the west coast (figure 1). The position of the dip equator since 1909 , as determined by various workers, is shown in figure 2 , which includes the present estimate. The repeat observations of magnetic inclination made by Chatterjee (1970) at the equatorial stations of Mandapam and Tirunelveli are plotted in figure 3. The sense of movement of the dip equator as per figures 2 and 3 is in accordance with the secular variation of $Z$ at equatorial stations.

Cain (1969) estimated the northward movement of the dip equator in the Indian region to be 2.2 to $3.3 \mathrm{~km}$ /year, whereas the later estimate (Report 1972) put it at $5 \mathrm{~km} /$ year. The present rate of southward migration works out to be $2.4 \mathrm{~km} /$ year. The dip values are also estimated at the survey stations by substituting the coefficients in the spherical harmonic expansion. The thirteenth degree and order spherical harmonic coefficients derived using MAGSAT data (Langel et al 1980) are used for calculation. The 


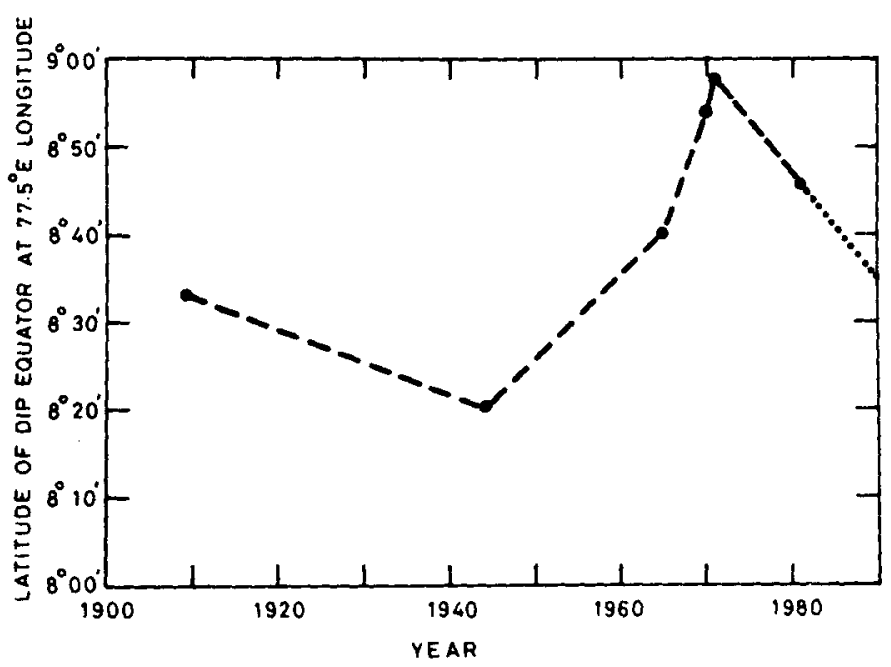

Figure 2. Position of DE at $77.5^{\circ}$ longitude since 1910 .

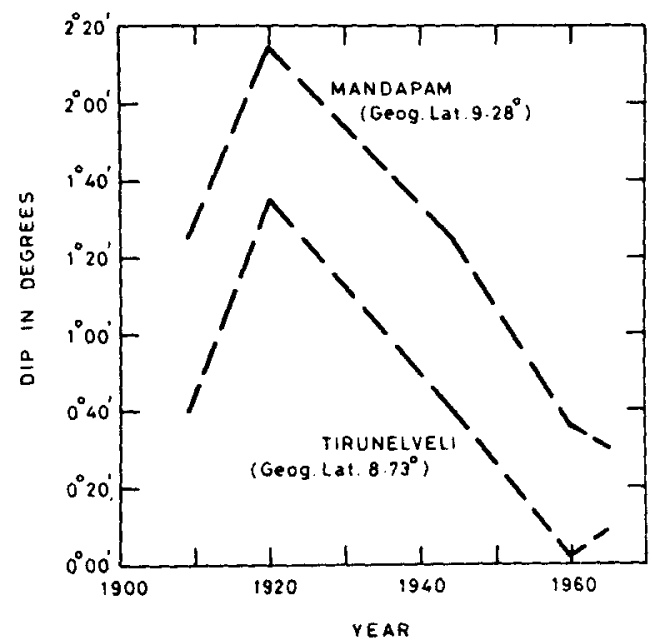

Figure 3. DE migration inferred from the repeat observations of inclination at Mandapam and at Tirunelveli since 1909.

calculated equator lies close to the observed dip equator and both intersect at $8^{\circ} 42 \cdot 5^{\prime} \mathrm{N}$ lat. and $77^{\circ} 15^{\prime} \mathrm{E}$ long.

The station locations with near-zero dip values (figure 1) are spread over a region of about $10^{\prime}$ in latitude (18 $\mathrm{km}$ approximately) signifying that, in India there appears to be a dip-equatorial belt, rather than a single linear dip equator; though a straight line representation is shown in figure 1 , as a first approximation.

However, one has to bear in mind that part of the scatter observed could have been caused by (a) the observational errors and (b) the errors involved in correcting the data for diurnal variation, inspite of the best possible care taken to minimize these errors. 
Also, there could be a contribution by the different subsurface geological setting at different station locations.

Further, it is noteworthy that if the present trend of southward migration (figure 2) of the dip equator continues, it would reach its 1909 latitude by the year 1990, apparently representing one full cycle of migration in the Indian region with its mean position approximately at $8^{\circ} 35^{\prime} \mathrm{N}$. Lat, with a periodicity of about $80 \mathrm{yr}$ as pointed out by Srivastava and Habiba Abbas (1977). This coincides with the known 80 yr spectral peak in the secular variation of the geomagnetic field at Alibag (Bhargava and Yacob 1970).

Thus, presently the dip equator is migrating southward as a direct consequence of the secular variation of the magnetic field components observed at the surface of the earth, which is believed to be related to the core dynamics.

\section{Acknowledgement}

The authors thank Shri T S Sastry of NGRI, for providing the tracings of the $Z$-magnetograms of the Etaiyapuram equatorial observatory for the period of survey. Thanks are also due to Dr G K Rangarajan of our Institute for helpful suggestions.

\section{References}

Bhargava B N and Yacob A 1970 J. Atmos. Terr. Phys. 32365

Cain J C 1969 The locations of dip equator, Proc. 3rd Int. Symp. Equatorial Aeronomy, Ahmedabad, Feb. 3-8, 1969 Vol. I-A, 172

Chatterjee J 1970 Proc. Seminar On Problems of the Equatorial Electrojet, Physical Research Lab, Ahmedabad, India 8 Aug. 1970

Langel R A, Estes R H, Mead G D, Fabiano E B and Lancaster E R 1980 Geophys. Res. Lett. 7793

Murty A V S, Subramanian Y H and Yacob A 1975 Proc. Symp. on Equatorial Geomagnetic Phenomena, Indian Institute of Geomagnetism Bombay, 126

Rastogi R G 1974 J. Geophys. Res. 791503

Rastogi R G and Sastri N S 1974 J. Geomag. Geoelectr. 26529

Report 1972 Geophys. Res. Bull. 10167

Sanker Narayan P V and Ramanujachary K R 1971 Nature (London) 23137

Sastri N S and Jayakar R W 1970 Indian J. Meteorol. Geophys. 21279

Srivastava B J and Habiba Abbas 1977 J. Geomag. Geoelectr. 2951

Sugiura M 1953 J. Geophys. Res. 58558

Tarpley J D 1973 J. Atmos. Terr. Phys. 351063

Yacob A 1966 Indian J. Meteorol. Geophys. 17271 